\title{
Novel Technology of Modifying the Surface of Biodegradable Vascular Grafts with RGD Peptides: Effect on the Surface Structure and Physical and Mechanical Properties
}

\author{
DOI: 10.17691/stm2019.11.3.02
}

Received September 3, 2018

L.V. Antonova, MD, DSc, Head of the Laboratory of Cell Technologies ${ }^{1}$;

V.N. Silnikov, DSc, Head of the Laboratory of Organic Synthesis;

T.V. Glushkova, PhD, Researcher, Laboratory of New Biomaterials ${ }^{1}$;

L.S. Koroleva, PhD, Researcher, Laboratory of Organic Synthesis 2 ;

I.Yu. Serpokrilova, PhD, Junior Researcher, Laboratory of Organic Synthesis;

V.V. Sevostyanova, PhD, Researcher, Laboratory of Cell Technologies ${ }^{1}$;

E.O. Krivkina, Junior Researcher, Laboratory of Cell Technologies ${ }^{1}$;

E.A. Senokosova, Junior Researcher, Laboratory of Cell Technologies ${ }^{1}$.

A.V. Mironov, Junior Researcher, Laboratory of Cell Technologies';

Yu.A. Kudryavtseva, DSc, Head of Experimental and Clinical Cardiology Department ${ }^{1}$;

L.S. Barbarash, MD, DSc, Professor, Academician of the Russian Academy of Sciences, Chief Researcher ${ }^{1}$

${ }^{1}$ Research Institute for Complex Issues of Cardiovascular Diseases, 6 Sosnovy Blvd, Kemerovo, 650002, Russia; ${ }^{2}$ Institute of Chemical Biology and Fundamental Medicine, Siberian Branch of the Russian Academy of Sciences, 8 Lavrentiev Avenue, Novosibirsk, 630090, Russia

The aim of the study was to assess the effectiveness of a new technology of modifying biodegradable small-diameter vascular grafts from polyhydroxybutyrate/valerate (PHBV) and polycaprolactone (PCL) with RGD peptides and its effect on the surface structure and physical and mechanical characteristics of these grafts.

Materials and Methods. Tubular polymer prostheses (matrices, grafts) $1.5 \mathrm{~mm}$ in diameter were fabricated using electrospinning method from the composition of PHBV and PCL polymers. Hexamethylendiamine, glutaraldehyde, ascorbic acid, and arginine-glycineaspartic acid were used to modify the surface of polymer scaffolds. The quality of the modification performed was assessed using a ninhydrin test and by determining the arginine-containing peptide. The structure of the graft surfaces before and after modification was examined using scanning electron microscopy. Mechanical properties were evaluated by uniaxial tension with determination of ultimate tensile strength, relative elongation, and Young's modulus. The characteristics of the internal mammary artery (a. mammaria interna) were used as a control of these parameters, vascular synthetic ePTFE-based linear grafts served as a group of comparison.

Results. Presence of RGD peptides on the polymer surface was confirmed by a Sakaguchi test which is specific for arginine. The mode of modification did not alter the surface structure of the polymer grafts but resulted in the reduction of their rigidity by 1.6 times, strength by 3.9 times, and relative elongation by 1.7 times. The physical and mechanical properties of PHBV/PCL+RGD grafts approached those of the a. mammaria.

Conclusion. The developed technology of modifying the surfaces of PHBV/PCL-based vascular grafts with RGD peptides made it possible to obtain PHBV/PCL+RGD grafts with the physical and mechanical properties approaching to those of the native vessels without any changes of the surface structure.

Key words: biodegradable vascular grafts; modified vessel surfaces; RGD peptides; electrospinning; arginine-glycine-aspartic acid.

\section{Introduction}

Currently, a great number of methods of physical, chemical, and biological modification of tissueengineered construct surfaces are known aimed mainly at the improvement of biocompatibility of the material chosen for their fabrication. The whole spectrum of additional requirements is imposed to the items developed for the needs of cardiovascular surgery which ultimately ensure safe and reliable functioning of these items after implantation in the vascular bed. In particular, thromboresistance of internal surface of vascular grafts, which is provided in the native vessels by functioning of the preserved endothelial layer, guarantees long-term patency in the organism. Under physiological conditions, vascular endothelium possesses high thromboresistance

Corresponding author: Larisa V. Antonova, e-mail: antonova.la@mail.ru 
producing a large number of biologically active factors which are connected with homeostasis, fibrinolysis, impairment of vascular tone, permeability of vessels, growth factor synthesis [1].

One of the crucial factors of reliability of a smalldiameter vascular transplant is rapid formation of the endothelial lining on its internal surface that may provide athrombogenic effect and an adequate lumen of a future newly formed vessel. Formation of the endothelial layer in situ after graft (matrix, scaffold) implantation into the blood flow is possible owing to attraction or capturing of endothelial progenitor cells from the bloodstream which, after the adhesion to the porous graft surface, are capable of proliferation and completely fill in the surface differentiating further into mature endothelial cells [2].

In recent years, a number of strategies have been developed to make polymer surfaces selectively adhesive for endothelial cells in order to accelerate endothelialization. The majority of them use immobilization or fixation of specific cellular adhesion proteins and bioactive peptides on the surface [3].

Arginine-glycine-asparagine (RGD) represents a cellular adhesion site present on many proteins of the extracellular matrix [4]. This succession is one of the key ligands for integrins, receptors which are responsible for cellular adhesion, migration, proliferation, differentiation, and survival [5]. RGD peptide may be considered a common integrin-binding motif. Bioactive RGDcontaining peptides possess a more simple structure and a higher chemical stability compared to proteins. Due to artificial synthesis, various configurations of RGD peptides having low immunogenicity and different potential of interaction with cells can be obtained.

Diverse kinds of synthetic materials modified with various RGD forms have been tested for the effectiveness of adhesion of mature and progenitor endothelial cells [6-9]. RGD tripeptide has been proved to accelerate endothelialization of the polymer material surfaces [10 12]. Tropism to endothelial cells makes RGD peptides and their configurations ideal agents for modification of medical devices contacting with blood and requiring rapid endothelialization of the material surface.

The effectiveness of cellular adhesion has been established to be influenced not only by the RGD configuration but also by the length of the linker groups binding the RGD peptide to the surface of the modified construction. The best results have been obtained with the longest linker groups [13].

The results of our previous investigations showed that the degree of primary surface modification grew with the time of treatment with hexamethylenediamine. The maximal density of graft surface modification during $60 \mathrm{~min}$ was $8.9 \mathrm{nM} / \mathrm{cm}^{2}$ [14]. However, the physical and mechanical characteristics of the grafts have become much worse [15].

It is known that any modification process must not alter the structure and affect negatively physical and mechanical characteristics of the final device. This is the main requirement to these procedures. A safety margin is necessary for the items functioning under the conditions of the pulsing blood flow to prevent aneurysm formation till a new tissue is generated in situ. Elastic deformation properties must be as close to the properties of a native vessel as possible in order to provide the compliance between the vessel and the graft being implanted. The above-mentioned requirements are especially critical for the devices designed for cardiovascular surgery.

The aim of the study was to assess the effectiveness of a new technology of modifying biodegradable smalldiameter vascular grafts from polyhydroxybutyrate/ valerate (PHBV) and polycaprolactone (PCL) with RGD peptides and its effect on the surface structure and physical and mechanical characteristics of these grafts.

\section{Materials and Methods}

Fabrication of tubular PHBV/PCL scaffolds. Tubular polymer matrices of $1.5 \mathrm{~mm}$ in diameter were fabricated using a Nanon-01A electrospinning machine (MECC Co. Ltd, Japan) from the composition of PHBV with $10 \%$ content of valerate (Sigma-Aldrich, USA) and PCL with 80,000 kDa molecular mass (Sigma-Aldrich, USA). Non-polar organic solvent, chemically pure chloroform (Vecton, Russia), was used for our work. The ratio of polymers in the solution was 1:2.

Modifying PHBVIPCL matrices with RGD peptides. To modify the surfaces of $1.5 \mathrm{~mm}$ tubular PHBV/PCL polymer matrices, hexamethylenediamine, glutaraldehyde, ninhydrin, ascorbic acid (Sigma-Aldrich, USA), and RGD (NanoTech-S, Russia) have been used. First, matrices were treated with $10 \%$ solution of hexamethylenediamine in the mixture of isopropanol and water $(1: 1)$ at $37^{\circ} \mathrm{C}$ for $30 \mathrm{~min}$ with a 2-fold reduction of modification time [14, 15]. Each graft here and further was in a separate $15 \mathrm{ml}$ reactor in the horizontal position with constant swinging.

Then, the tubular PHBV/PCL scaffolds were successively washed with a triple volume of the following reagents:

1) 1:1 mixture from isopropanol and water;

2) bidistilled water;

3) $0.1 \%$ Triton $X-100$ solution;

4) bidistilled water.

After the last washing, the tubular PHBV/PCL scaffolds were treated with $2 \%$ solution of glutaraldehyde for $3 \mathrm{~h}$ at $24^{\circ} \mathrm{C}$, washed with a triple volume of bidistilled water, placed in the solution of $0.2 \mathrm{mg} / \mathrm{ml}$ peptide in $50 \mathrm{mM}$ carbonate buffer $(\mathrm{pH} 8.5)$ containing $2.5 \mathrm{mM}$ sodium cyanoborohydride, and kept for $4 \mathrm{~h}$ at $24^{\circ} \mathrm{C}$.

After RGD peptide binding, the grafts were washed in a triple reagent volume:

1) $0.1 \%$ Triton $X-100$ solution;

2) bidistilled water.

Identification of arginine-containing peptide [16, 17]. $0.5 \mathrm{ml}$ of $\alpha$-naphthol solution $(0.01 \%$ solution in $95 \%$ ethyl alcohol with $5 \%$ carbamide) was added to $1 \mathrm{~cm}^{2}$ of a 
graft specimen. After a uniform wetting of the specimens, $50 \mu \mathrm{l}$ of $2 \mathrm{~N} \mathrm{NaOH}$ solution in alcohol was introduced into the solution. $5 \mathrm{~min}$ later, $0.5 \mathrm{ml}$ of bromine solution $(2 \%$ solution in $8 \%$ aqueous $\mathrm{NaOH}$ solution) was added to the reaction mixtures. The specimen was incubated for $12 \mathrm{~h}$ at room temperature. Its orange-red coloration indicated the presence of arginine guanidine group.

Scanning electron microscopy of matrix surfaces. The structure of the inner surface and the wall thickness of $0.5 \times 0.5 \mathrm{~mm}$ tubular nonwoven PHBV/PCL scaffolds unmodified and modified with RGD peptides $(n=5$ in each group) was examined using a scanning electron S-3400N microscope (Hitachi, Japan) under a high vacuum condition. Before the microscopy, gold and palladium were deposited on the specimens using a vacuum SC-7640 sputter coater (Quorum Technologies, England).

Physical and mechanical testing of the biodegradable vascular grafts. Mechanical properties were tested by uniaxial tension in compliance with a standard GOST 270-75. The specimens were cut in a longitudinal direction of a vascular segment. For the control, the parameters of the human internal mammary artery (a. mammaria) were used as a gold standard. Segments of a. mammaria were collected during aortocoronary bypass operation in patients signed a written informed consent for this procedure. A synthetic vascular ePTFE-based graft widely used in cardiovascular surgery was tested for comparison.

The tests were carried out using a universal testing system Zwick/Roell (Zwick GmbH, Germany) with a $50 \mathrm{~N}$ transducer and a crossbar moving at a speed of $10 \mathrm{~mm} /$ min. Ultimate strength was assessed as the maximal tensile stress (MPa) before destruction and elastic deformation properties by the relative elongation before the beginning of specimen destruction (\%) and Young's modulus ( $\mathrm{MPa}$ ) which was determined within the range of physiological pressure $(80-120 \mathrm{~mm} \mathrm{Hg})$.
Statistics. The obtained data were processed by conventional methods using applied software package Statistica 6.0 (StatSoft, Inc., USA) for processing medical and biological information. The distribution character in the samples was evaluated using Kolmagorov-Smirnov criterion. For the distribution different from normal the data were presented as median (Me) and quartiles (25\% and $75 \%$ ). For normal distribution, the data were presented as mean (M) and error of mean $(\sigma)$. Statistical significance of differences between two independent groups was assessed using nonparametric MannWhitney U-test or Student's t-test. Differences were considered significant at $p<0.05$.

\section{Results and Discussion}

The density of modifying the graft surfaces with RGD peptides for $30 \mathrm{~min}$ was $6.3 \mathrm{nM} / \mathrm{cm}^{2}$. Presence of the peptides on the polymer surface was verified by Sakaguchi test for arginine detection [16, 17]. Coloration of the specimen did not disappear after washing which indicated covalent coupling of the peptide. The control specimen free of RGD peptide became light yellow and its coloration disappeared during washings. Thus, the effectiveness of modifying the tubular PHBV/PCL scaffold surface with RGD peptides for 30 min reducing substantially the duration of the modifying procedure has been verified.

PHBV/PCL grafts modified and non-modified with RGD peptides possessed a highly porous structure with 170-250 $\mu \mathrm{m}$ wall thickness and homogeneous fibers (Figure 1).

An average fiber diameter and average pore area in the grafts were $2.63 \pm 1.14 \mu \mathrm{m}$ and $47.13 \pm 23.0 \mu \mathrm{m}^{2}$, respectively, at about $50.0 \%$ porosity. RGD peptide modification did not significantly influence these parameters. In contrast to non-modified specimens, the polymer grafts conjugated with RGD peptides
Figure 1. Scanning electron microscopy of PHBV/PCL grafts non-modified and modified with RGD peptides:

(a) cross section of the non-modified PHBVI PCL graft wall, $\times 200$; (b) inner surface of the non-modified PHBV/PCL graft, $\times 1000$; (c) cross section of the PHBV/PCL+RGD graft wall, $\times 150$; (d) inner surface of the PHBV/PCL+RGD graft, $\times 1000$
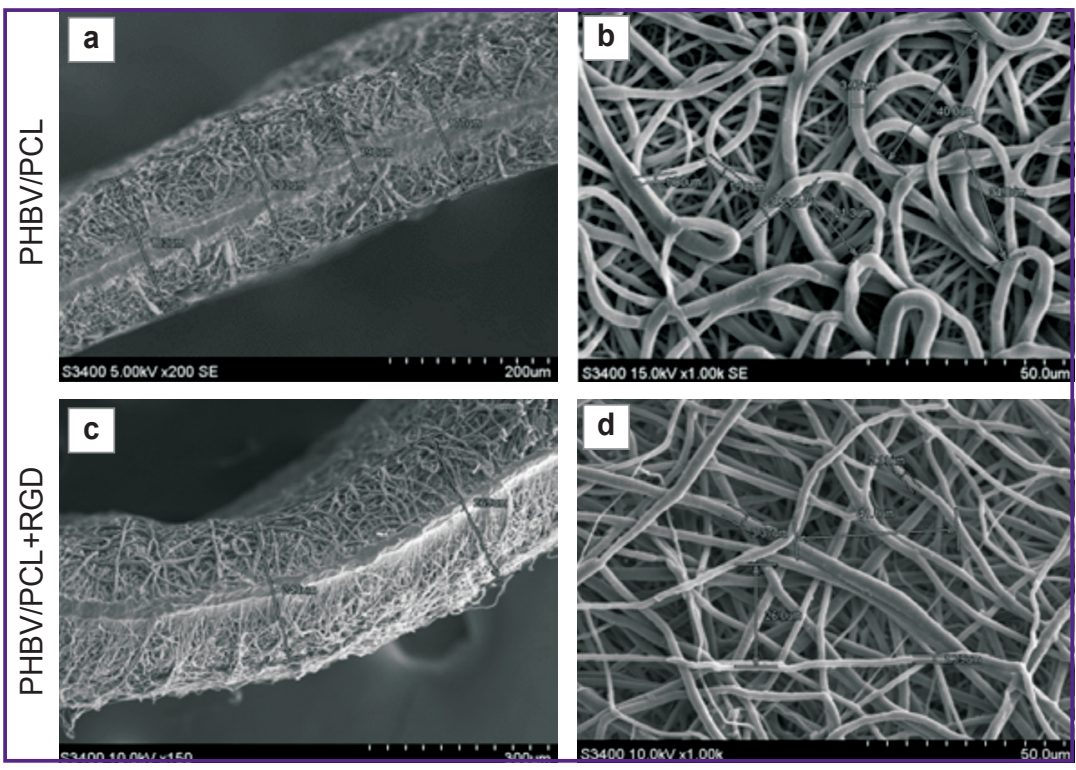
had bumps on the polymer fibers. These irregularities conceivably represent RGD biomolecules immobilized on the surface.

The elastic deformation properties of the ePTFEbased vascular graft did not differ significantly whereas its strength characteristics were 3.9 times higher than those of a. mammaria $(p<0.05)$ (see the Table).

The mechanical properties of non-modified vascular PHBV/PCL-based grafts have been found not to comply with those in the native vessels and ePTFE-based vascular grafts being characterized by a high rigidity, strength, and relative elongation. Values of Young's modulus for PHBV/PCL grafts were 10 times higher than for a. mammaria $(p<0.05)$. The strength of non-modified PHBV/PCL grafts was 2.8 times and relative elongation 14.5 times higher relative to these parameters for a. mammaria $(p<0.05)$. Its strength did not differ from that of the synthetic vascular ePTFE graft $(p<0.05)$.

Rigidity is an especially critical property for the compliance with the vessel into which the graft is planned to be implanted. Significant mismatch in the rigidity values for the repaired vessel and vascular graft may provoke later hypertrophy of neointima or thrombosis. Therefore, elimination of rigidity was the main task to be solved during modification of vascular PHBV/PCL grafts with RGD peptides. Modification of $\mathrm{PHBV} / \mathrm{PCL}$ grafts with RGD peptides resulted in alteration of physical and mechanical characteristics of the specimens (see the Table): 1.7-fold reduction of relative elongation and 1.6 -fold reduction of rigidity relative to the non-modified analogs have been noted $(p<0.05)$.

After the conducted modification with RGD peptides, the ultimate tensile strength of the vascular PHBV/PCL grafts became 3.9 times lower $(p<0.05)$ than before the procedure leading to the levelling of the difference in these values with a. mammaria. The PHBV/PCL+RGD grafts had statistically significantly greater capability to elongation (8.4 and 6.4 times higher, respectively) and high rigidity (7.6 and 6.4 times higher, respectively) relative to the values for a. mammaria and synthetic ePTFE grafts $(p<0.05)$.

The material response to the mechanical load under the increased resistance manifests itself by the growth of stress in the material at insignificant elongations being just the situation that we observed for the grafts irrespective of the modification within the range of physiological loads. Despite a significant decrease of rigidity and relative elongation for $\mathrm{PHBV} / \mathrm{PCL}$ grafts modified with RGD peptides $(p \leq 0.05)$, the diagrams reflecting stress/deformation ratio demonstrate mechanical behavior of the modified grafts different from a. mammaria and ePTFE (Figure 2).

Mechanical properties of the grafts compared to the native vessels and synthetic vascular grafts (Me [25\%; 75\%])

\begin{tabular}{lccc}
\hline \multicolumn{1}{c}{ Groups } & Ultimate tensile strength (MPa) & Relative elongation (\%) & Young's modulus (MPa) \\
\hline A. mammaria $(n=6)$ & $2.48(1.36 ; 3.25)$ & $29.72(23.51 ; 39.62)$ & $2.34(1.53 ; 2.95)$ \\
\hline ePTFE $(n=6)$ & $9.70(8.26 ; 10.97)^{*}$ & $38.69(32.23 ; 52.13)$ & $2.31(1.65 ; 2.78)$ \\
\hline PHBV/PCL $(n=6)$ & $7.05(5.58 ; 8.02)^{*}$ & $431.33(397.30 ; 574.55)^{\star \#}$ & $28.0(22.0 ; 32.9)^{* \#}$ \\
PHBV/PCL+RGD $(n=6)$ & $1.82(1.51 ; 2.04)^{\#+}$ & $248.40(163.55 ; 288.23)^{\star \#+}$ & $17.85(16.20 ; 19.40)^{* \#+}$ \\
\hline
\end{tabular}

$\mathrm{N}$ o t e: statistically significant value differences $(p<0.05)$ : * from a. mammaria; \# from polymer ePTFE graft; ${ }^{+}$from polymer PHBV/PCL graft.

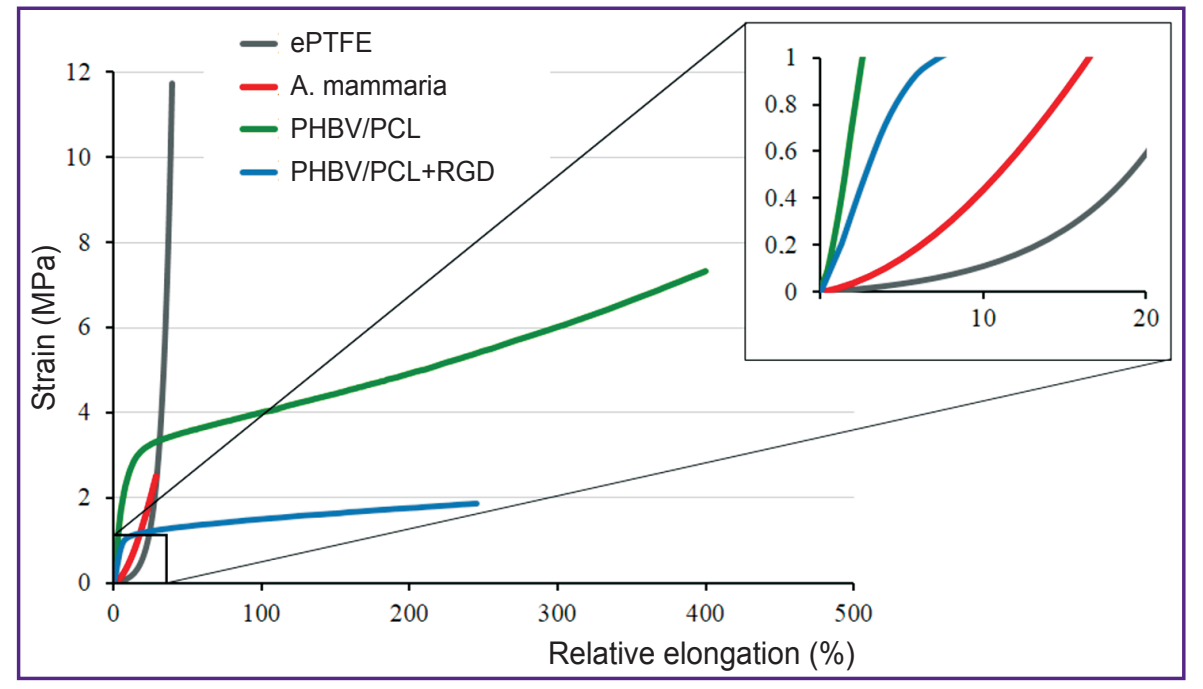

Figure 2. Mechanical properties of polymer grafts:

stress-deformation ratio before the beginning of destruction; stressdeformation under physiological pressure conditions 
This fact indicates the necessity of further investigations aimed at optimization of elastic and deformation properties of polymer grafts.

\section{Conclusion}

The mode of modifying polymer biodegradable tubular scaffolds from PHBV/PCL with RGD peptides for $30 \mathrm{~min}$ used in this work did not lead to statistically significant alteration of their surface. At the same time, the rigidity of the grafts and their ability to elongation decreased after the conducted modification which brought physical and mechanical properties of the vascular PHBV/PCL+RGD grafts closer to those of the native vessels.

Further experiments on modification of biodegradable tubular scaffolds require a more careful selection of optimal time and modes of action of modifying agents on the examined polymer. It is necessary both for achieving maximal modification quality and prevention of harmful effect of surfactants used in the process of modification with peptides on the polymer surface.

Study funding. The work was done at the Research Institute for Complex Issues of Cardiovascular Diseases and Institute of Chemical Biology and Fundamental Medicine, Siberian Branch of the Russian Academy of Sciences using the funds of the integration project "Biodegradable small-diameter vascular graft modified functionally with active peptides" of the complex program of fundamental scientific researches of the Siberian Branch of Russian Academy of Sciences II.1 (No.05462018-0001). The block of works to be performed by the Research Institute for Complex Issues of Cardiovascular Diseases: "Development of scientific bases for fabrication and modification of a biodegradable vascular graft and its testing in vitro". The Institute of Chemical Biology and Fundamental Medicine was responsible for the block: "Modification of polymer scaffolds with functionally active peptides and the assessment of its quality".

Conflicts of interest. The authors have no conflicts of interest to declare.

\section{References}

1. Fadini G.P., Rattazzi M., Matsumoto T., Asahara T., Khosla S. Emerging role of circulating calcifying cells in the bone-vascular axis. Circulation 2012; 125(22): 2772-2781, https://doi.org/10.1161/circulationaha.112.090860.

2. Lee K.-W., Johnson N.R., Gao J., Wang Y. Human progenitor cell recruitment via SDF-1 $\alpha$ coacervate-laden PGS vascular grafts. Biomaterials 2013; 34(38): 9877-9885, https:// doi.org/10.1016/j.biomaterials.2013.08.082.

3. Ren X., Feng Y., Guo J., Wang H., Li Q., Yang J., Hao X., Lv J., Ma N., Li W. Surface modification and endothelialization of biomaterials as potential scaffolds for vascular tissue engineering applications. Chem Soc Rev 2015; 44(15): 5680-5742, https://doi.org/10.1039/c4cs00483c.

4. Wang F., Li Y., Shen Y., Wang A., Wang S., Xie T. The functions and applications of RGD in tumor therapy and tissue engineering. Int J Mol Sci 2013; 14(7): 13447-13462, https:// doi.org/10.3390/ijms140713447.

5. Harburger D.S., Calderwood D.A. Integrin signalling at a glance. J Cell Sci 2008; 122(2): 159-163, https://doi. org/10.1242/jcs.018093.

6. Tiwari A., Kidane A., Salacinski H., Punshon G., Hamilton G., Seifalian A.M. Improving endothelial cell retention for single stage seeding of prosthetic grafts: use of polymer sequences of arginine-glycine-aspartate. Eur $J$ Vasc Endovasc Surg 2003; 25(4): 325-329, https://doi.org/10.1053/ ejvs.2002.1854

7. Kidane A.G., Punshon G., Salacinski H.J., Ramesh B., Dooley A., Olbrich M., Heitz J., Hamilton G., Seifalian A.M. Incorporation of a lauric acid-conjugated GRGDS peptide directly into the matrix of a poly(carbonate-urea)urethane polymer for use in cardiovascular bypass graft applications. J Biomed Mater Res A 2006; 79(3): 606-617, https://doi. org/10.1002/jbm.a.30817.

8. Alobaid N., Salacinski H.J., Sales K.M., Ramesh B., Kannan R.Y., Hamilton G., Seifalian A.M. Nanocomposite containing bioactive peptides promote endothelialisation by circulating progenitor cells: an in vitro evaluation. Eur $J$ Vasc Endovasc Surg 2006; 32(1): 76-83, https://doi.org/10.1016/j. ejvs.2005.11.034.

9. Salacinski H.J., Hamilton G., Seifalian A.M. Surface functionalization and grafting of heparin and/or RGD by an aqueous-based process to a poly(carbonate-urea)urethane cardiovascular graft for cellular engineering applications. J Biomed Mater Res A 2003; 66(3): 688-697, https://doi. org/10.1002/jbm.a.10020.

10. Gabriel M., van Nieuw Amerongen G.P., van Hinsbergh V.W.M., van Nieuw Amerongen A.V., Zentner A. Direct grafting of RGD-motif-containing peptide on the surface of polycaprolactone films. J Biomater Sci Polym Ed 2006; 17(5): 567-577, https://doi.org/10.1163/ 156856206776986288.

11. Chung T.-W., Yang M.-G., Liu D.-Z., Chen W.-P., Pan C.-I., Wang S.-S. Enhancing growth human endothelial cells on Arg-Gly-Asp (RGD) embedded poly(epsiloncaprolactone) (PCL) surface with nanometer scale of surface disturbance. J Biomed Mater Res A 2004; 72(2): 213-219, https://doi.org/10.1002/jbm.a.30225.

12. Zheng W., Guan D., Teng Y., Wang Z., Zhang S., Wang L., Kong D., Zhang J. Functionalization of PCL fibrous membrane with RGD peptide by a naturally occurring condensation reaction. Chinese Science Bulletin 2014; 59(22): 2776-2784, https://doi.org/10.1007/s11434-014-0336-0.

13. Gabriel M., Nazmi K., Dahm M., Zentner A., Vahl C.-F., Strand D. Covalent RGD modification of the inner pore surface of polycaprolactone scaffolds. J Biomater Sci Polym Ed 2012; 23(7): 941-953, https://doi.org/10.1163/092050611x566793.

14. Antonova L.V., Silnikov V.N., Khanova M.Yu., Koroleva L.S., Serpokrilova I.Yu., Velikanova E.A., Matveeva V.G., Senokosova E.A., Mironov A.V., Krivkina E.O., Kudryavtseva Yu.A., Barbarash L.S. Adhesion, proliferation and viability of human umbilical vein endothelial cells cultured on the surface of biodegradable non-woven matrices modified with RGD peptides. Vestnik transplantologii $i$ iskusstvennyh organov 2019; 21(1): 142-152, https://doi.org/10.15825/19951191-2019-1-142-152.

15. Antonova L.V., Silnikov V.N., Sevostyanova V.V., Yuzhalin A.E., Koroleva L.S., Velikanova E.A., Mironov A.V., Godovikova T.S., Kutikhin A.G., Glushkova T.V., 


\section{ADVANCED RESEARCHES}

Serpokrylova I.Yu., Senokosova E.A., Matveeva V.G., Khanova M.Yu., Akentyeva T.N., Krivkina E.O., Kudryavtseva Yu.A., Barbarash L.S. Biocompatibility of small-diameter vascular grafts in different modes of RGD modification. Polymers 2019; 11(1): 174, https://doi. org/10.3390/polym11010174.

16. Lin H.B., Sun W., Mosher D.F., García-Echeverría C., Schaufelberger K., Lelkes P.I., Cooper S.L. Synthesis, surface, and cell-adhesion properties of polyurethanes containing covalently grafted RGD-peptides. J Biomed Mater Res 1994; 28(3): 329-342, https://doi.org/10.1002/ jbm.820280307.

17. Parniak M.A., Lange G., Viswanatha T. Quantitative determination of monosubstituted guanidines: a comparative study of different procedures. J Biochem Biophys Methods 1983; 7(4): 267-276, https://doi.org/10.1016/0165-022x(83)90051-9. 